\title{
The Impact of Coporate Website on Dissemination of Research Information Among Stakeholders in Nigeria
}

\author{
Chinedum Eunice Chibudike ${ }^{1}$ \\ Planning, Technology Transfer and \\ Information management \\ Federal Institute of Industrial Research \\ Oshodi (F.I.I.R.O.) Lagos, Nigeria \\ Email: nedumchibu [AT] yahoo.com
}

\author{
Viola Nwachukwu Nichola Okpara ${ }^{4}$ \\ Food Technology Department \\ Federal Institute of Industrial Research \\ Oshodi (F.I.I.R.O.) Lagos, Nigeria \\ Email: Viola3us [AT] yahoo.com
}

\author{
Haruna $\mathrm{Abdu}^{2}$ \\ Department of Computer Science \\ Federal University Lokoja \\ Kogi State, Nigeria \\ Email: haruna.abdu [AT] \\ fulokoja.edu.ng
}

\author{
Nkemdilim Ifeanyi $\mathrm{Obi}^{5}$ \\ National Oil Spill Detection and \\ Response Agency (NOSDRA) \\ Abuja-Nigeria \\ Email: n.i.odegaobi [AT] gmail.com
}

\author{
Henry Okwudili Chibudike ${ }^{3}$ \\ Chemical, Fiber and Environmental \\ Technology Department \\ Federal Institute of Industrial Research, \\ Oshodi, Lagos-Nigeria \\ Email: henrychibudike [AT] gmail.com
}

\author{
Olubamike Adetutu Adeyoju ${ }^{6}$ \\ Production, Analytical and Laboratory \\ Management, Federal Institute of \\ Industrial Research, Oshodi, F.I.I.R.O., \\ Lagos-Nigeria
}

Email: Olubamike2004 [AT] gmail.com

\begin{abstract}
This study accesses the influence of an official website as one that has been licensed by using an authority to signify itself or its houses online. Individuals, companies, governments, and different organizations can be such an authority. An internet portal is a web-based platform that gives employees, clients and suppliers with a single get right of entry to factor to information. ${ }^{8}$ A web portal can be used to supply the consumer with customized data such as employee training, protection manuals or a customer profile. A web portal can additionally be used to beautify the collaboration of information and improve the way employees, customers and suppliers interact with your commercial enterprise [7]. There are couple of reasons why an MSMEs will seem toward net portal development. This study was once made in two classes of lookup institutes: Health institutes and economic/social institutes. Comparison figures point out that there is no sizable difference in phrases of presence of a respectable website of Health Institutes and Economic/social institutes. Health Institutes have extra capability to diffuse their improvements to public than Economic/social institutes, using their website as a verbal exchange device of lookup findings dissemination. The comparisons of use of professional website, goal audiences were carried out as well as reliability check in percentages to allow conclusive results.
\end{abstract}

Keywords- Website, Health Institute, Economics/social Institute, web portal and authority.

\section{INTRODUCTION}

Websites are doubtless the foremost vital part of the web. The term is usually used inconsistently, therefore, to form it clear once and for all, this text answers the question: what's web site an internet site web site? The central page of a website is named a home page. this can be typically the primary page you see after your decision an internet site up and may even be referred to as a 'start page' or 'index page'. From here onward, the user delves into the site's subpages. Digital net presence allows content like texts, images, and videos to be displayed on the web. ${ }^{10}$ There are several reasons why business folks would like a representative website: to tell potential customers concerning product and services, to represent the corporate, to alter contact with totally different departments, or to distribute merchandise on-line. For personal users, an internet site provides them the possibility to actively participate publicly affairs. ${ }^{9}$ There are also| personal sites that contain informative material or are used for diversion a summary of the foremost well-liked sites will be found below. By inserting a link to your own web site next to your social network profile, you increase the probabilities of catching the eye of potential employers, interested parties, or similar folks. A web site's giant reach is actually one amongst the explanations for the growing range of websites in recent years: A site or website could be a central location of sites that are connected and accessed by visiting the house page of the web site employing a browser as an example, the pc Hope web site address uniform resource locator (Uniform Resource Locator) is https://www.computerhope.com. From our home page, you'll get access to any of the net pages.

\section{BACKGROUND}

Tim Berners-Lee, a British researcher, created the World Wide Web (WWW) in 1989, while working at CERN. ${ }^{1}$ The Web was initially considered and created to satisfy the need for mechanized data dividing among researchers in colleges and 
foundations around the world [13]. CERN is anything but a segregated lab, but instead the point of convergence for a broad local area that incorporates in excess of 17000 researchers from more than 100 nations. Despite the fact that they normally invest some energy on the CERN site, the researchers generally work at colleges and public labs in their nations of origin. Solid specialized devices are hence essential [14].

The essential thought of the WWW was to blend the developing advancements of PCs, information organizations and hypertext into an incredible and simple to utilize worldwide data framework.

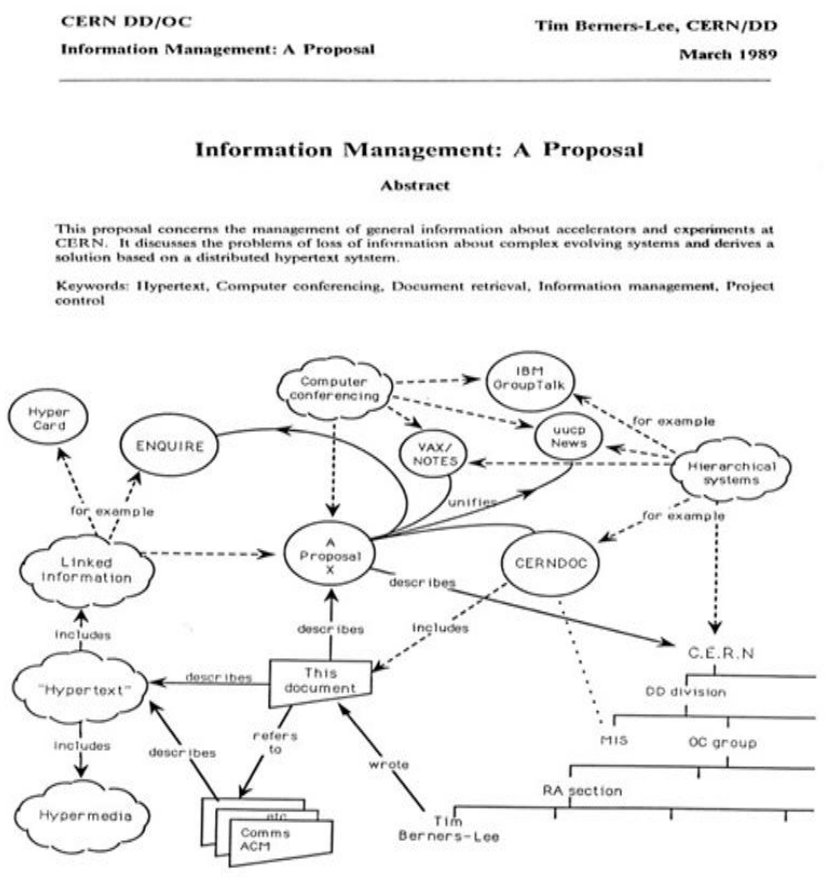

Figure 1: An image of the first page of Tim Berners-Lee's proposal for the World Wide Web in March 1989

Tim Berners-Lee composed the first proposal for the World Wide Web in March 1989 and his subsequent proposal in May 1990. Along with Belgian frameworks engineer Robert Cailliau, this was formalized as an administration proposal in November 1990. This illustrated the primary ideas and it characterized significant terms behind the Web. The record portrayed a "hypertext project" called "WorldWideWeb" in which a "web" of "hypertext reports" could be seen by "browsers"[1].

Before the finish of 1990, Tim Berners-Lee had the main Web worker and program ready for action at CERN, showing his thoughts. He built up the code for his Web worker on a Next PC. To forestall it being inadvertently turned off, the PC had a transcribed name in red ink [13]:

\section{Justification}

This study can raise the information of the industries and public of the areas that web site enhances like
- Improve Your Advertising Effectiveness.

- Save cash on Printing and Distribution prices.

- Easy Access to New Customers.

- Easy to Use and Update.

- Improve Productivity.

- Educate Your Customers.

- Expand Your Market.

- Extend your native Reach.

\section{RELATED WORKS}

\section{Measuring Effectiveness of Websites}

In early 1997, a form was sent to the content suppliers of the 206 Australian internet sites known as relevant to Australian farm business (Rin and Groves 1999). To assess user demand, most content suppliers accept email feedback on their websites et al get a sign by observance their hit counters to envision what percentage folks read their sites. Observance usage through 'hits' ranges from easy observance of hit counts through to additional elaborated analysis of access and transfer statistics across totally different areas of an internet site. The subsequent Table 1. Provides some details of forty-eight respondents who answered the form and provided data on usage [11].

The late 1980s were the design's dark ages.

The idea of the "world wide web" is thought to have been first mentioned in a short story by Murray Leinster in 1946. However, physicist Tim Berner-Lee is credited with its official (albeit unintentional) invention in 1989. He used hypertext to create an index of pages on the framework when constructing a database of software for a client. This developed into what we now refer to as web pages. The dark ages of web design is regarded as such because programmers worked on black screens with pixels. As you can see in this mock-up of what Google might have looked like in the 1980s, designs were made up of symbols and tabulation (also known as the TAB key).

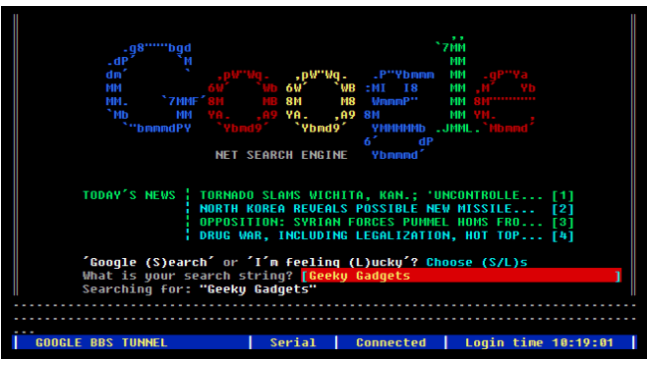

Figure 2: Google

Although we may now consider this age of web design to be primitive, many designers continue to be inspired by the post-modern style of the 1980s. With its pixelated backdrop, icons, and blocky text, this web design layout stands out in a sea of ultra-modern websites.

\section{METHODOLOGY AND DATA ANALYSIS}

Primary data gathered were checked for exactness, coded, and afterward went into a PC. Investigation of quantitative 
information was led concerning the destinations of the examination utilizing the Software Package for factual examination (SPSS).

Frequencies and rates were processed to portray different issues identified with site and they were introduced in tables and figures to show the distinctions and choices of respondents on which the conversation is based.

Examination of change was directed to survey how much methods for inclusion, idealness and importance of sites differ from one another. In the event that the likelihood was discovered to be at under 0.05 critical levels a post hoc test (Duncan various examination test) was rushed to think about methods [4].

TABLE I. HITS EVERY MONTH AND \% OF RESPONDENTS WHO ADDRESSED THE INQUIRY, AUSTRALIA

\begin{tabular}{|l|l|}
\hline & \% of responses \\
\hline Under 500 & 43 \\
500 to 2000 & 3 \\
2000 to 10,000 & 20 \\
10,000 to 20,000 & 7 \\
20,000 to 50,000 & 3 \\
50,000 to 100,000 & 7 \\
\hline
\end{tabular}

Content investigation of subjective information was directed to distinguish the socially developed nature of the real world. The cycle included distinguishing, coding and arranging the essential examples in the information. The initial step was to appropriately examine the information through perusing the gathered data. Furthermore, the data was then arranged by recognizing topics or examples for example thoughts, ideas, practices, cooperation, occurrences, wording or expressions utilized. Here the information gathered were made into field notes.

\section{RESULTS AND DISCUSSION}

To understand the discussions of the result of this study; the following statistical analysis were discussed: -

- Comparison of Presence of an Official Website.

○ Reliability.

○ Summary Item Statistics.

- ANOVA with Friedman's Test.

- Presence of an official website in health and Econ/soc Research Institutes.

- Comparison of purpose of the website in health and Econ/soc Research Institutes.

- $\quad$ Target audiences for the website.
- Comparison of effects of Website in both Research institutes.

\section{A. Comparison of Presence of an Official Website}

The study was made in two categories of research institutes: Health institutes and economic/social institutes. Comparison figures indicate that there is no significant difference in terms of presence of an official website of Health Institutes and Economic/social institutes. However, the Health Institutes figure $(100 \%)$ is little higher than Economic/social institutes figure (98\%).

TABLE II. PRESENCE OF AN OFFICIAL WEBSITE HEALTH AND ECON/SOC RESEARCH INSTITUTES

\begin{tabular}{|c|c|c|}
\hline & Health Res (\%) & Econ/soc Res (\%) \\
\hline Yes & 100 & 98 \\
No & 0 & 2 \\
\hline
\end{tabular}

\section{B. Reliability}

Reliability indicates the degree to which a survey instrument is consistent with what it measures (Litwin, 1995). A split half reliability test was conducted to determine the consistency of the survey instrument. To carry out the split half reliability test, the questionnaire was administered to 30 MSMEs who were randomly selected from a list of MSMEs in Lagos. Lagos is in the western part of Nigeria. According to Israel (2012) a sample size greater or equal to 20 can yield meaningful results in a survey study. A Kendall's coefficient of concordance of 0.67 was obtained which showed that the questionnaire was reliable. A post hoc analysis using the pretest sample generated a Kendall's coefficient of concordance of 0.7 to confirm the reliability of the questionnaire.

TABLE III. RELIABILITY

\begin{tabular}{|c|c|c|}
\hline \multicolumn{3}{|c|}{ Inter-Item Correlation Matrix } \\
\hline & Health Res (\%) & Econ/soc Res (\%) \\
\hline Health Res (\%) & 1.000 & 1.000 \\
\hline Econ/soc Res (\%) & 1.000 & 1.000 \\
\hline
\end{tabular}

\begin{tabular}{|l|c|l|l|l|l|l|l|}
\hline \multicolumn{7}{|c|}{ Table 2.2 Summary Item Statistics } \\
& Mean & $\begin{array}{l}\text { Minimu } \\
\mathrm{m}\end{array}$ & $\begin{array}{l}\text { Maximu } \\
\mathrm{m}\end{array}$ & Range & $\begin{array}{l}\text { Maximum } \\
\text { Minimum }\end{array}$ & Variance & $\begin{array}{l}\text { No. of } \\
\text { Items }\end{array}$ \\
\hline Item Means & 50.000 & 50.000 & 50.000 & .000 & 1.000 & .000 & 2 \\
\hline $\begin{array}{l}\text { Item } \\
\text { Variances }\end{array}$ & 4804.00 & 4608.00 & 5000.00 & 392.000 & 1.085 & 76832.00 & 2 \\
\hline
\end{tabular}




\begin{tabular}{|c|c|c|c|c|c|c|}
\hline \multicolumn{7}{|c|}{ Table 2.3 ANOVA with Friedman's Test } \\
\hline & & $\begin{array}{ll}\text { Sum } & \text { of } \\
\text { Squares } & \end{array}$ & df & \begin{tabular}{|c} 
Mean \\
Square
\end{tabular} & $\begin{array}{l}\text { Friedman's } \\
\text { Chi-Square }\end{array}$ & Sig \\
\hline \multicolumn{2}{|c|}{ Between People } & 9604.000 & 1 & 9604.000 & & \\
\hline \multirow[t]{3}{*}{$\begin{array}{l}\text { Within } \\
\text { People }\end{array}$} & $\begin{array}{l}\text { Betwee } \\
\text { n Items }\end{array}$ & $.670^{\mathrm{a}}$ & 1 & .670 & .670 & 1.000 \\
\hline & Residual & 4.000 & 1 & 4.000 & & \\
\hline & Total & 4.000 & 2 & 2.000 & & \\
\hline \multicolumn{2}{|c|}{ Total } & 9608.000 & 3 & 3202.667 & & \\
\hline
\end{tabular}

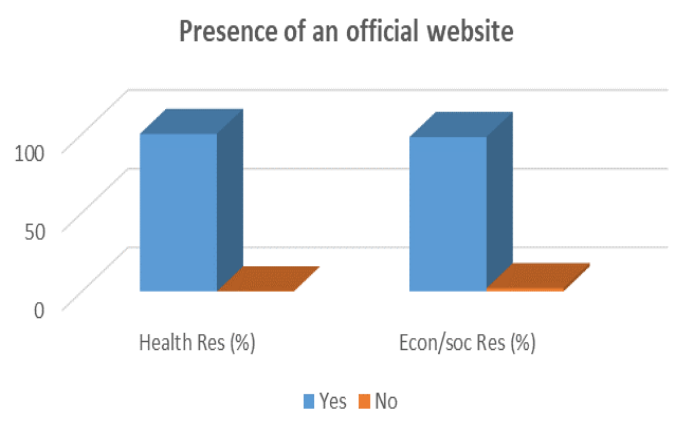

Figure 3: Presence of an official website

\section{Comparison of Purpose of the Website}

Even though more Economic/social institutes recognized a website as a more cost- effective and/or efficient channel of communication than Health Institutes, they use it as a vehicle for providing service to clients comparatively less than Health Institutes.

TABLE IV. COMPARISON OF PURPOSE OF THE WEBSITE IN HEALTH AND ECON/SOC RESEARCH INSTITUTES

\begin{tabular}{|l|l|c|}
\hline \multicolumn{1}{|c|}{ Purpose } & Health Res (\%) & Econ/soc Res (\%) \\
\hline Provision of useful information for & 100 & 100 \\
users & 95 & 95 \\
Publicity for your institute & 82 & 56 \\
$\begin{array}{l}\text { As a vehicle for providing service to } \\
\text { clients }\end{array}$ & 12 & 16 \\
$\begin{array}{l}\text { As means of conducting commercial } \\
\text { or financial transactions }\end{array}$ & 53 & 73 \\
$\begin{array}{l}\text { As more cost-effective and/or efficient } \\
\text { channel of communication }\end{array}$ & \\
\hline
\end{tabular}

Source: Author survey (2016)

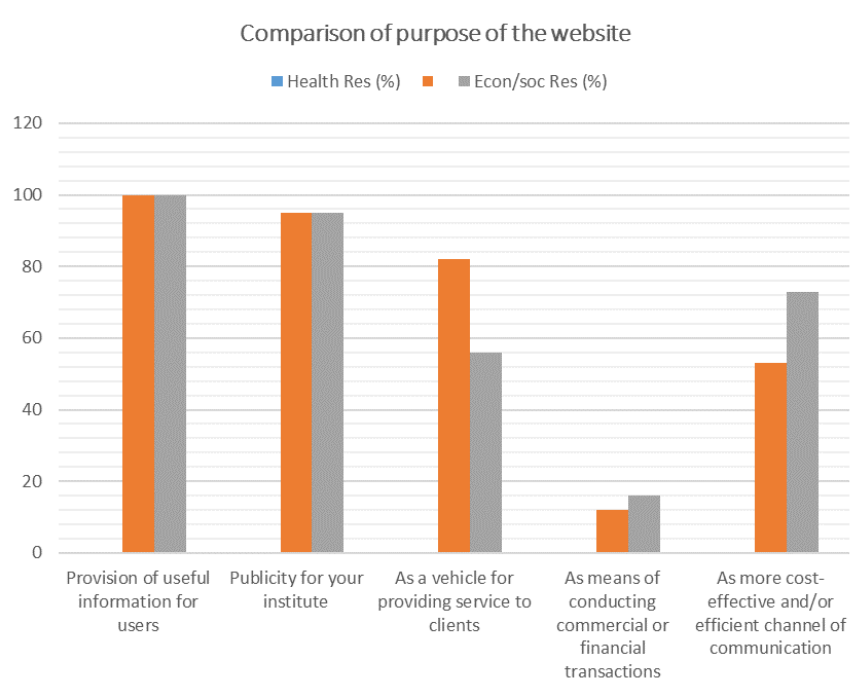

Figure 4: Comparison of purpose of the website in Health and Econ/soc Research Institutes

\section{Comparison of Target Audiences for the Website}

Comparative percentages of target audiences for the internet site indicate that Health Institutes have much higher percentage rates than Economic/social institutes in every targeted audience except professional/technical support. It was very clear that all Research institutes target MSMEs as their top priority.

TABLE V. TARGET AUDIENCES FOR THE WEBSITES IN BOTH INSITUTES

\begin{tabular}{|l|c|l|}
\hline Target audiences & Health Res (\%) & Econ/soc Res (\%) \\
\hline General public & 73 & 60 \\
MSMEs & 37 & 63 \\
Professional/ & 53 & 37 \\
technical support & 67 & 83 \\
Their own staff (i.e. an intranet) & 87 & 67 \\
\hline
\end{tabular}

Source: Author survey (2016). 


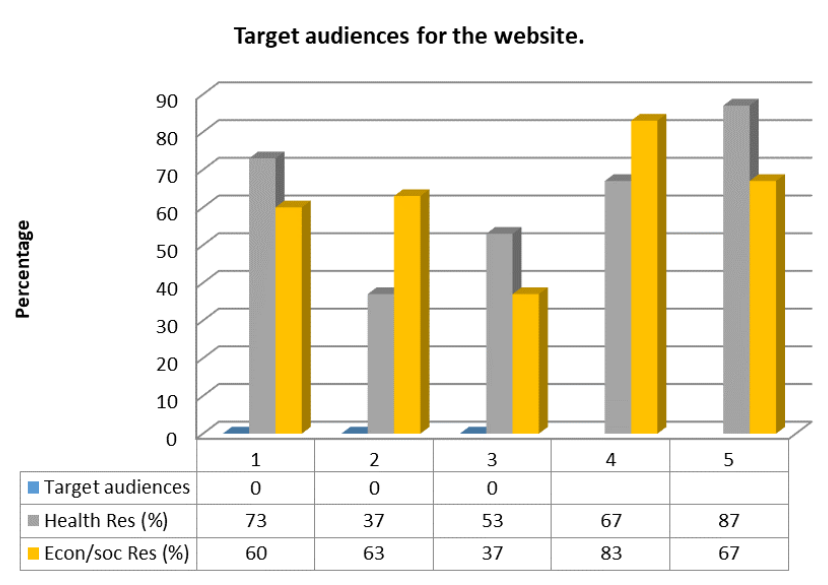

Figure 5: Target audiences for the websites in both Institutes.

In conclusion, Health Institutes have more ability to diffuse their innovations to public than Economic/social institutes, using their website as a communication tool of research findings dissemination.

\section{E. Comparison of effects of Website in both Research institutes}

It is interesting that the proportional representation of reasons to use website for innovation diffusion in Health Institutes were relatively less than Economic/social institutes in terms of percentage weight. Every Economic/social institutes interviewed agreed that website is an effective as well an efficient communication tool. However, Health Institutes did not agree to that extent. Health Institutes stated that low maintenance cost was the least likely reason to use website, while Economic/social institutes stated low overhead and establishment cost.

TABLE VI. EFFECTS OF WEBSITES IN BOTH INSTITUTES COMPARED

\begin{tabular}{|l|c|c|}
\hline \multicolumn{1}{|c|}{ Effect of website } & Health Res (\%) & Econ/soc Res (\%) \\
\hline Minimal effort & 53 & 57 \\
Ideal data about an advancement Low & 70 & 72 \\
overhead and foundation costs Low & 15 & 7 \\
upkeep costs & 7 & 4 \\
Low representative preparing costs & 15 & 13 \\
Advantageous & 73 & 77 \\
Simple to oversee/alter data & 60 & 97 \\
Successful & 53 & 100 \\
Proficient & 67 & 100 \\
Can join with other media such as & 53 & 87 \\
DVDs, sound video camera, etc. & & \\
\hline
\end{tabular}

Source: Author survey (2016).

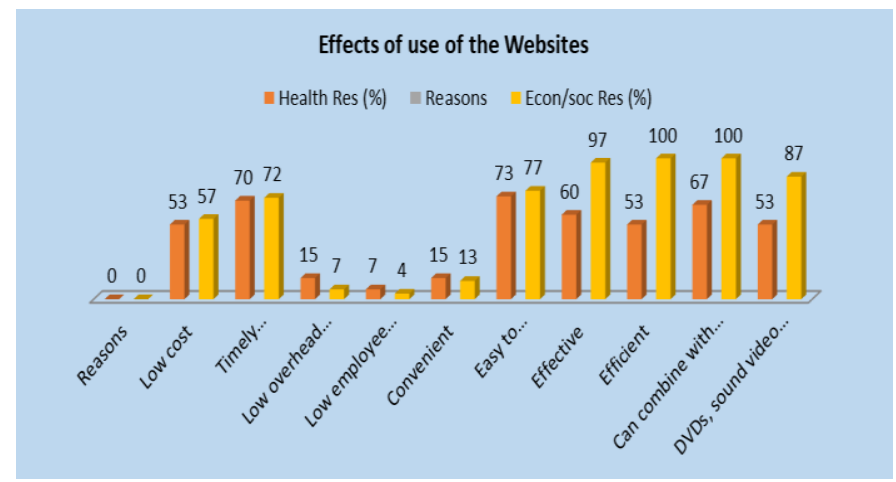

Figure 6: Effects of the use of Websites in Health and Econ/soc Research Institutes

This table shows the reasons why public site will help in innovation diffusion. As survey made in different research institutes of the two categories proves appreciable percentage of low cost, timeliness, low cost maintenance and low employee training cost and convenient. Since the conditions are favorable. There is every need for model or system (public website).

\section{RECOMMENDATION}

Lately, every independent venture ought to have a site. With incredibly minimal effort at the passage level, it's hard to envision the motivation behind why any organization of any size ought not have a site. As numerous easy to use, free and open-source content-administration frameworks are made accessible to help individuals with Web plan, it is even simple to assemble an essential private company site without an expert Web creator. This is prescribed because of the accompanying:

\section{Low-Cost Advertising}

The Website has a far more extensive arrive at more than some other type of publicizing. As much time it takes to develop enough traffic to your site to make a beneficial effect on your organization's showcasing effort, it costs nearly to accomplish so. The online presence of your organization is found in your site; through it, all the ad of your business is done around the Web on interpersonal interaction locales, and furthermore discussions and through compensation per-click publicizing programs [2].

\section{Visibility}

Visibility increment is one main consideration that makes a site significant. In any event, when individuals have found out about your organization, they actually need to complete exploration online first, prior to going out to look for the organization. In giving a guide and bearings to your organization's shops or workplaces on your site helps guests and decreases the trouble and inconvenience of finding the spot [1].

\section{Accessibility}

The truth stays that site is on the web and open 24 hours per day, and all year long. For this, your hand clients and potential clients can visit your site to hotspot for help or data about new items and administrations at whatever point they wish. Your 
site will be important and consistently accessible asset of data which would some way or another just be open during and after your organization's business hours [5].

\section{Sales}

Sales of items are made in your site whenever. Potential clients are not confined to just business hours. All things being equal, they are permitted to go on the web and buy items at whatever point they need. A site that is with an internet business or online shop can give a sensational lift in deals [3].

\section{CONCLUSION}

Sites as perhaps the most far reaching business prerequisites today have improved the web designer industry. Working of site is presumably one of the quickest developing assistance territories today. Every year assortments of new sites are dispatched and gain a spot in the web crawlers. In time past, the basic role of sites was for training, however on seeing their methodology, they ended up being a ground-breaking instrument for businesspeople.

In the event that your site has been very much planned, it could turn into an amazing source to snatch more prominent customers to your business. One of the significant advantages that business people for the most part achieve from sites is that the sites help to elevate their business to any edge of the world without additional expenses [7]. There is need to make additional costs or dispatch another limited time mission to advance your organization or item in some different spots. In this manner two winged animals can be hit with a stone. One of simple advancement of the item is cost saving through sites. In order to promote your products, the website has be promoted so as to get the attention of MSMEs. Make sure that your website is worthwhile for promoting your website. Go for a website professional that will give you exactly the same thing that you want for your website. Be sure of the website designed and its layout. The website professionals need to give your website a look that is suits the company's theme. Use of variant colors or flash website builder tools can be an enhance option. ${ }^{6}$ And then come to the website content, the more you are open with your services the more the chances of getting closer to your clients. If the information is delivered in a planned and systematic manner, the visitors will find it easy to read and they will be able to get through each and every clause that you have mentioned. This not only delivers a better impression of your company among other stakeholders and MSMEs but also develops a feeling of trust in the minds of visitors.

\section{ACKNOWLEDGMENT}

We appreciate the efforts and encouragements of all our loved ones, our amiable colleagues at F.I.I.R.O and also the anonymous reviewers whose comments and suggestions have been helpful.

\section{REFERENCES}

[1] Campbell, B and Goodman, J,"HAM: a general purpose Hypertext Abstract Machine",in Communications of the ACM July 1988 Vol 31, No. 7

[2] Gupta, D.K. (2005) Modern encyclopedia of media and mass communication. Rajat Publications, New Delhi,India.Book-2007.

[3] Hassan, M.S., Hassan, M.A., Samah, B.A., Ismail, N. and Shafrill, H.A.M. (2008) Use of Information and Communication Technologies among agri-based entrepreneurs in Malayasia.

[4] Heilig,G. (2003) Information Society and the countryside: can internet based system bring income alternatives to rural areas? (in:) J.Banski; J. Oswinski (eds.). Alternatives for European Rural Areas, Rural Areas and Development, 1, ERDN,Warszawa, 65-79.

[5] IFPRI. (2013) Global Policy Food Report. Farmers markets and power of connectivity.

[6] IICD. (2007) How ICT can make a difference in agricultural livelihood. The Common Wealth Ministers Reference

[7] Jabir, A. (2011) Use of quality information for decision -making among livestock Farmers: Role of ICT .Livestock

[8] Meera, S.N., Jhamtani, A., \& Rao, D.U.M. (2004) Information and Communication Technology in agricultural development: A comparative analysis of three projects from India. Agricultural Research and Extension Network Paper, (134).

[9] Mittal, S. and Mehar. M. (2012) How mobile phones lead to growth of small farmers? Evidence from India. Quarterly Journal of International Agriculture 51 (3):227-244.

[10] Mittal, S. and Mehar. M. (2013) Agricultural information networks, information needs and risk management strategies: a survey of farmers in Indo-Gangetic plains of India. Socio-economic working paper 10. Mexico, D.F.:CIMMYT.

[11] Mtega, W.P and Msungu, A.C. (2013) Using Information and Communication Technologies for enhancing the accessibility of agricultural information for improved agricultural production in Tanzania. The Electronic Journal on Information Systems in Developing Countries 56 (1):1-14.

[12] Munyua, H. (2000) Information and Communication Technologies for rural development and food security: Lessons from field experiences in developing countries. Sustainable Development Department (SD), FAO of the United Nations.

[13] Nelson, T.H. "Getting it out of our system" in Information Retrieval: A Critical Review", G. Schechter, ed. Thomson Books, Washington D.C., 1967, 191-210 [SMISH88]

[14] Smish, J.B and Weiss, S.F,"An Overview of Hypertext",in Communications of the ACM, July 1988 Vol 31, No. 7,and other articles in the same special "Hypertext" issue. [CAMP88] 